\title{
Diseño De Un Sendero Turistico Interpretativo Para La Comuna Kichwa Mandari Panga, Amazonia Ecuador
}

\author{
Ing. Rita Sulema Lara Vásconez, M.Sc. \\ Arq. Oswaldo David Malla Pacheco, M.Sc. \\ Ing. Isabel Dominguéz. M.Sc. \\ Ing. Hilter Farley Figueroa Saavedra, M.Sc \\ Arq. Carlos Hidalgo Mendoza, M.Sc. \\ Licda. Abigail Garrido Valle \\ Lic. Manuel Abarca. MSc
}

Escuela Superior Politécnica del Chimborazo, Ecuador

Doi:10.19044/esj.2019.v15n14p193 URL:http://dx.doi.org/10.19044/esj.2019.v15n14p193

\section{Resumen}

La presente investigación tiene como objetivo: diseñar un sendero turístico interpretativo para la comunidad Kichwa Mandaripanga, en la Amazonía Ecuatoriana, para lo cual se utilizó los siguientes métodos científicos: el método deductivo, método de observación descriptivo, métodos empíricos teóricos y estadísticos, se destaca el diseño de senderos turísticos interpretativos como una herramienta educativa que permite comunicar el valor de la conservación del patrimonio de los recursos naturales y culturales, se introducen términos como: biodiversidad, turismo alternativo, senderismo interpretación ambiental, se analiza el impacto ambiental como el efecto que produce una determinada acción humana sobre el medio ambiente en sus distintos aspectos, para finalmente ofrecer un modelo de sendero turístico interpretativo para promover la identidad local y nacional y proporcionar un servicio turístico adicional en los entornos naturales aumentando el valor recreativo, y de aprendizaje durante la estancia de visita.

Palabras clave: Turismo rural, biodiversidad, turismo alternativo, senderismo, interpretación ambiental. 


\title{
Desing of a Interpretative Tourist Trail for the Kichwa Community Mandari Panga, Ecuador Amazon
}

\author{
Ing. Rita Sulema Lara Vásconez, M.Sc. \\ Arq. Oswaldo David Malla Pacheco, M.Sc. \\ Ing. Isabel Dominguéz. M.Sc. \\ Ing. Hilter Farley Figueroa Saavedra, M.Sc \\ Arq. Carlos Hidalgo Mendoza, M.Sc. \\ Licda. Abigail Garrido Valle \\ Lic. Manuel Abarca. MSc
}

Escuela Superior Politécnica del Chimborazo, Ecuador

\begin{abstract}
The objective of this research is to design an interpretive tourist trail for the Kichwa Mandaripanga community in Amazon Ecuadorian Region, for which the following scientific methods were used: deductive method, descriptive observation method, empirical theoretical and statistical methods, it stands out the design of interpretive tourist trails as an educational tool that allows to communicate the value of heritage conservation of natural and cultural resources, it introduces terms such as: biodiversity, alternative tourism, trekking, environmental interpretation, and the environmental impact is analyzed as an effect that produces a certain human action on the environment in its different aspects and finally offers a model of interpretive tourist trail to promote the local and national identity, also provide an additional tourist service in natural environments thus increasing the recreational and learning value, during the term of the visit.
\end{abstract}

Keywords: Rural tourism, biodiversity, alternative tourism, trekking, environmental interpretation

\section{Introducción:}

Los senderos interpretativos son reconocidos como una excelente herramienta para la enseñanza del ambiente, despertando la curiosidad por conocer sobre la biodiversidad de un lugar. Aunque se encuentran generalmente en áreas naturales protegidas, zoológicos, jardines botánicos, zonas arqueológicas y museos (Pellegrini, 2006). De acuerdo con los datos de 
la Organización Mundial del Turismo (OMT), el segmento turístico que actualmente experimenta el más acelerado crecimiento es el llamado turismo alternativo, es decir el turismo que tiene como destino la naturaleza y que incluye todas aquellas prácticas turísticas conocidas como turismo especializado: turismo de aventura, científico, cinegético, montañismo, campismo, buceo, safari fotográfico, canotaje, espeleología, ecoturismo, etc. (Fundación Biosfera, 2015). El Turismo Alternativo comprende principalmente al Turismo Rural, al Turismo Aventura y al Ecoturismo. Las tres modalidades se caracterizan por desarrollarse en áreas naturales, notándose un estrecho contacto entre los turistas y la naturaleza. Su bajo impacto se debe fundamentalmente a que son realizadas por un número muy reducido de turistas, que demandan servicios personalizados; y las actividades y servicios se distribuyen de manera dispersa, a diferencia del turismo tradicional donde servicios, actividades y turistas presentan una notoria concentración espacial (Wearing \& Neil, 2000). El sendero es una pequeña ruta, camino o huella señalizada o no que pasa generalmente por las sendas y caminos rurales para practicar el senderismo así mismo permite recorrer con facilidad un área determinada. Los senderos cumplen varias funciones, tales como: a. Servir de acceso y paseo para los visitantes. b. Ser un medio para el desarrollo de actividades educativas c. Servir para los propósitos administrativos del área protegida.

La interpretación ambiental es una actividad educativa orientada a revelar significados y relaciones mediante el uso de objetos originales, a través de experiencias de primera mano y medios ilustrativos. La interpretación ambiental, lejos de comunicar información literal, lo que busca es transmitir ideas y relaciones a partir de un acercamiento directo entre la audiencia y los recursos que se interpretan. Para lograrlo se utilizan diferentes técnicas que ayudan a las personas a entender y apreciar lo que se observa. Los senderos interpretativos son una herramienta educativa que permite comunicar el valor de la conservación del patrimonio de los recursos naturales y culturales, permitiendo a los visitantes tener un contacto directo con los valores sobre los que se quiere dar un mensaje. Su objetivo es mostrar la flora, fauna y otros valores naturales del área de una manera atractiva para los visitantes. En algunos casos, estos senderos requieren de un guía o intérprete que explique lo que se puede observar. Un sendero interpretativo puede ser exitoso si mediante la conservación y recreación se logra: a. Generar ingresos para la conservación. b. Crear empleos ya sea directamente en la construcción y mantenimiento del sendero. c. Proporcionar un servicio turístico adicional en los entornos naturales, aumentando el valor recreativo y aprendizaje durantee la estancia del visitante. d. Promover la identidad local y nacional. La identidad nacional étnica se fortalece con afirmación del valor de los recursos naturales y culturales por parte de la comunidad y los visitantes. e. Promover 
el valor del área entre los escolares y la comunidad local en general a través de la educación e interpretación ambiental. (Comité de Senderos de la Federación Española, 1996). La señalización es la parte de la ciencia de la comunicación visual que estudia las relaciones funcionales entre los signos de orientación en el espacio y el comportamiento de los individuos. Es de carácter "autodidáctico", entendiéndose éste como modo de relación entre los individuos y su entorno (MINTUR, 2007).

El análisis de los recursos naturales se basa en el inventario de atractivos turísticos del MINTUR, en este contexto es importante diferenciar entre recursos y atractivos turísticos, la definición es la siguiente: Recurso Turístico. Son sitios naturales y manifestaciones culturales que merezcan ser visitadas o admiradas por los visitantes. Son el fundamento para el desarrollo posterior de la atracción y son la materia prima de futuras atracciones. Atractivo Turístico. Son recursos turísticos que tengan elementos aptos para la explotación del turismo, esto es, dotados al menos con accesos y preferiblemente con servicios básicos, por lo tanto, es muy importante el diseño de senderos turísticos interpretativos, en zonas rurales dotadas de belleza natural, escénica y paisajística, lo cual permite desarrollar el turismo comunitario y contribuye a mejorar las condiciones de vida de los habitantes.

En Orellana, las comunidades viven en condiciones de pobreza extrema (46\% de la población) y demandan de iniciativas que articulen la generación de propuestas y condiciones sostenibles y sustentables de acuerdo a las diversas realidades locales y regionales y que promuevan un desarrollo equitativo. Éste es el caso de la comuna Kichwa Mandari Panga, propuesta que les permita su convivencia en armonía con la naturaleza (Sumak Kawsay) aprovechando el potencial turístico de su territorio y de su cultura (GADPO, 2014).

En los últimos años, la demanda turística por sitios de patrimonio natural y cultural prístinos registra un crecimiento exponencial tanto en el país como en el extranjero y si bien la mayor parte de la actividad se desarrolla a través de lo que se conoce como turismo "masivo" o "convencional", es cierto que existe un número cada vez mayor de turistas que busca contacto con las culturas autóctonas y con los espacios naturales. Este segmento, en su mayoría de buen poder adquisitivo, a pesar de su pequeño tamaño dentro del mercado turístico global, está alcanzando un $20 \%$ de la demanda internacional y no cesa de crecer. El ecoturismo en particular, entendido como aquel motivado por el contacto de los visitantes con el entorno natural, se encuentra en notable crecimiento en el mundo. Dentro de esta modalidad, la utilización de la fauna silvestre se está transformando en uno de los principales ejes de desarrollo para muchos países en la actualidad (Albrieu \& Navarro, 2013).

Los procesos de comunicación sobre los valores del patrimonio cultural y de la biodiversidad de las diferentes regiones se vuelven cada día más 
relevantes para promover la conservación y el desarrollo. Una de las herramientas educativas que se plantea aplicar en áreas naturales protegidas son los senderos interpretativos, espacios donde se llevan a cabo actividades educativas que buscan la integración de la sociedad civil a los procesos de conservación de algún área en particular. Estos senderos permiten el contacto directo de los visitantes con los valores sobre o en torno a los cuales se quiere dar un mensaje. Cada sendero tiene un objetivo específico que se sustenta en el desarrollo de las actividades, centrando la atención en un aspecto que el visitante pueda interiorizar y que a la vez sirva de hilo conductor de los contenidos del mensaje (SECTUR, 2004).

\section{OBJETIVO:}

Diseñar un sendero turístico para la comuna Kichwa Mandari Panga, para la Amazonia del Ecuador.

\section{Metodología}

Se utilizó los siguientes métodos científicos: el método deductivo, método de observación descriptivo, métodos empíricos teóricos y estadísticos.

La investigación se realizó a partir de un diagnóstico situacional, para analizar los problemas que tienen los habitantes de la comunidad Mandar panga, con respecto al turismo de naturaleza, en conjunto con los diferentes actores involucrados, buscando las mejores alternativas para que la actividad turística funcione de la mejor manera y principalmente mejore las condiciones de vida de la comunidad Mandaripanga, para el diagnóstico se utilizaron metodologías participativas como: lluvia de ideas, árbol de problemas, matriz FODA.

El análisis de los recursos naturales existentes, se basa en la aplicación de la metodología de inventariaríación de atractivos turísticos del Ministerio de Turismo del Ecuador, para cuya clasificación se procede de la siguiente manera.

\section{ETAPAS PARA LA ELABORAR EL INVENTARIO DE ATRACTIVOS CLASIFICACION DE LOS ATRACTIVOS}

Consiste en identificar claramente la categoría, tipo y subtipo, al cual pertenece el atractivo a inventariar.

La clasificación de las categorías de atractivos en esta metodología se la hace en dos grupos: SITIOS NATURALES Y MANIFESTACIONES CULTURALES. Ambas categorías se agrupan en tipos y subtipos.

En la categoría de Sitios naturales se reconocen los tipos: Montañas, Planicies, Desiertos. Ambientes Lacustre, Ríos, Bosques, Aguas Subterráneas, Fenómenos Espeleológicos, Costas o Litorales, Ambientes Marinos, Tierras Insulares, Sistema de Áreas protegidas. 
En la categoría Manifestaciones Culturales se reconocen los tipos: históricos, Etnográficos, Realizaciones Técnicas y Científicas, Realizaciones Artísticas Contemporáneas y Acontecimientos Programados.

CATEGORÍA: Define los atributos que tiene un elemento y motivan la visita turística dependiendo de su naturaleza.

TIPO: $\quad$ Son los elementos de características similares en una categoría.

SUBTIPO: Son los elementos que caracterizan los tipos.

Las jerarquías establecidas son la siguientes:

\section{RECOPILACIÓN DE INFORMACIÓN}

En esta fase se selecciona tentativamente los atractivos para lo cual se investigan sus características relevantes. Esta fase de investigación es documental, cuya información debe obtenerse en las oficinas relacionadas con su manejo.

\section{TRABAJO DE CAMPO}

Consiste en la visita a efectuarse a los sitios para verificar la información sobre cada atractivo. Es el procedimiento mediante el cual se le asignan las características al atractivo.

El trabajo de campo debe ordenarse en función de los desplazamientos para estimar el tiempo total que demande esta actividad. Es recomendable dirigirse a las oficinas públicas que puedan dotar de información adicional, como Municipios y Consejos Cantonales, Gobernaciones, Casas Parroquiales, así como de informantes locales, y tratar de visitar con alguno de ellos el atractivo, del que se harán al menos 5 fotografías.

\subsubsection{EVALUACIÓN Y JERARQUIZACION}

Consiste en el análisis individual de cada atractivo, con el fin de calificarlo en función de la información y las variables seleccionadas: calidad, apoyo y significado. Permite valorar los atractivos objetiva y subjetivamente.

1. Jerarquía IV: Atractivo excepcional de gran significación para el mercado turístico internacional, capaz por sí solo de motivar una importante corriente de visitantes actual o potencial.

2. Jerarquía III: Atractivo con rasgos excepcionales en un país, capaz de motivar una corriente actual o potencial de visitantes del mercado interno, y en menor porcentaje el internacional, ya sea por sí solos o en conjunto con otros atractivos contiguos.

3. Jerarquía II: Atractivo con algún rasgo llamativo, capaz de interesar a visitantes de larga distancia, ya sea del mercado interno, y receptivo, que hubiesen llegado a la zona por otras motivaciones turísticas, o de motivar 
corrientes turísticas actuales o potenciales, y atraer al turismo fronterizo de esparcimiento.

4. Jerarquía I: Atractivos sin mérito suficiente para considerarlos a nivel de las jerarquías anteriores, pero que igualmente forman parte del patrimonio turístico como elementos que pueden complementar a otros de mayor jerarquía en el desarrollo y funcionamiento de cualquiera de las unidades que integran el espacio turístico (MINTUR, 2014)

Se realizó un estudio morfológico del suelo para poder implementar el diseño del sendero que tiene dimensiones de $1 \mathrm{~m}$ a $2.10 \mathrm{~m}$ de ancho por 0.40 $\mathrm{m}$ de grosor. El diseño de la señalética posee elementos que permiten distinguir las rutas turísticas, del área seleccionada a partir de la identificación de los atractivos turísticos ubicados en el trazado del sendero y zona de influencia del proyecto, además en la señalética establecida se contempla puntos en donde se restringe zonas protegidas ( $\mathrm{Si}$ las hubiese) para los turistas que caminan por los tramos de sendero seleccionado.

- Criterios Arquitectónicos para el diseño del sendero auto guiado.

- Morfología del terreno.

Gráfico 1. Mapa Geomorfológico de la Provincia de Orellana

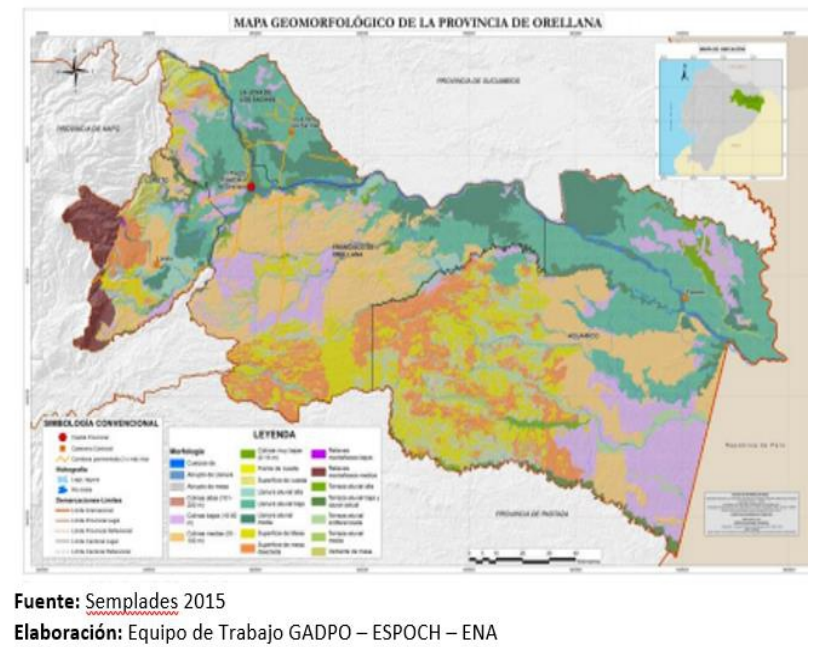

\section{Criterios Funcionales.}

- $\quad$ Funcionalidad. El proyecto tendrá flexibilidad para los ámbitos del esparcimiento, aprendizaje e interlocución entre las personas que acceden a esta zona.

- $\quad$ Forma. Los senderos se diseñarán en forma lineal.

Circulación. Circulación peatonal.

Bioclimática.

Espacios libres y cubiertas verdes para mejor confort térmico e interacción con la naturaleza. 


\section{Zonificación.}

Distribución de espacios de estancias, en puntos estratégicos, relacionándose con el contexto y las determinantes físicas del lugar.

\section{Criterios de Sostenibilidad.}

- $\quad$ Recursos. Manejo de materialidad y elementos propios del lugar para fácil consecución del mantenimiento de los mismos.

- Tecnología. Utilización de aerogeneradores domésticos para la implementación de luz artificial en las horas nocturnas y alimentación de aparatos electrónicos e implementación de reflectores de piso de bajo consumo tipo LED.

\section{Criterios Técnicos.}

- $\quad$ Se pretende implementar materiales de fácil consecución en la zona que contrasten con el contexto natural y sean amigables con el medio ambiente del sector.

\section{Resultados}

A. Resumen del Inventario de Atractivos Naturales Ubicados en la Zona de Influencia del Proyecto "Comuna Kichwa Mandari Panga"

Tabla 1. Resumen del Inventario de Atractivos Naturales

\begin{tabular}{|l|l|l|l|c|c|}
\hline $\begin{array}{l}\text { Nombre del Atractivo } \\
\text { Turístico }\end{array}$ & Categoría & Tipo & Subtipo & Jerarquía & Foto \\
\hline $\begin{array}{l}\text { Bosque humedo tropical } \\
\text { amazónico. }\end{array}$ & $\begin{array}{l}\text { Sitios } \\
\text { Naturales }\end{array}$ & Bosque & $\begin{array}{l}\text { Humedo tropical } \\
\text { amazónico. }\end{array}$ & IV & II \\
\hline Río Tiputini. & $\begin{array}{l}\text { Sitios } \\
\text { Naturales }\end{array}$ & Río & ---- & II \\
\hline Río Rumiyacu & $\begin{array}{l}\text { Sitios } \\
\text { Naturales }\end{array}$ & Río & --- & II & II \\
\hline $\begin{array}{l}\text { Laguna Nina Amarum } \\
\text { Cocha }\end{array}$ & $\begin{array}{l}\text { Sitios } \\
\text { Naturales }\end{array}$ & Laguna & ---- & \\
\hline Saladeros Panga & $\begin{array}{l}\text { Sitios } \\
\text { Naturales }\end{array}$ & Laguna & ---- & \\
\hline
\end{tabular}

En la tabla $\mathrm{N}^{\circ} 1$ uno se puede apreciar, un resumen de los principales atractivos turísticos naturales que se encuentran en el trazado del sendero y en la zona de influencia del proyecto.

\section{A. Jerarquización.}

La jerarquía se estableció a partir de la suma de los valores asignados a cada variable o factor, y en función de los puntos obtenidos se determinó el rango jerárquico en donde se ubica en sitio natural. 
Tabla 2. Valoración de las Jerarquías de Atractivos Turísticos.

\begin{tabular}{|c|c|c|c|c|c|c|c|c|c|c|c|c|c|}
\hline \multirow[b]{2}{*}{$\begin{array}{l}\text { NOMBRE DEL } \\
\text { ATRACTIVO }\end{array}$} & \multicolumn{2}{|c|}{ CALIDAD } & \multirow[b]{2}{*}{ 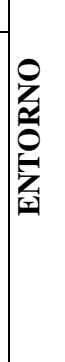 } & \multirow[b]{2}{*}{ 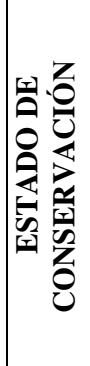 } & \multirow[b]{2}{*}{ 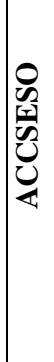 } & \multirow[b]{2}{*}{ 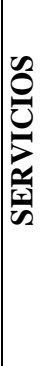 } & \multirow[b]{2}{*}{ 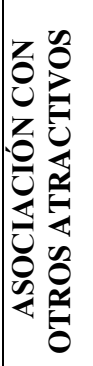 } & \multicolumn{4}{|c|}{ SIGNIFICADO } & \multirow[b]{2}{*}{ 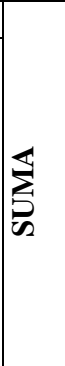 } & \multirow[b]{2}{*}{ 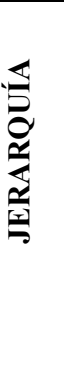 } \\
\hline & 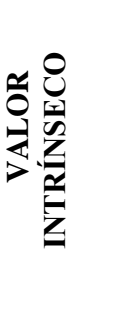 & 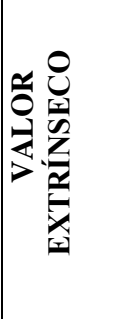 & & & & & & 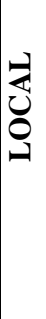 & $\begin{array}{l}3 \\
\vdots \\
0 \\
z \\
z \\
0 \\
0 \\
a \\
0\end{array}$ & $\begin{array}{l}\frac{1}{z} \\
0 \\
0 \\
\bar{u} \\
z \\
z\end{array}$ & 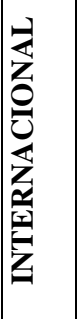 & & \\
\hline $\begin{array}{c}\text { BOSQUE HUMEDO } \\
\text { TROPICAL AMAZÓNICO } \\
\text { (PARQUE NACIONAL } \\
\text { YASUNÍ) }\end{array}$ & 15 & 15 & 10 & 10 & 5 & 3 & 5 & 2 & 4 & 7 & 12 & 88 & IV \\
\hline $\begin{array}{c}\text { BOSQUE HUMEDO } \\
\text { TROPICAL AMAZÓNICO }\end{array}$ & 15 & 15 & 10 & 10 & 5 & 3 & 5 & 4 & 4 & 8 & 4 & 79 & III \\
\hline RIO TIPUTINI & 10 & 8 & 8 & 7 & 5 & 3 & 5 & 2 & 0 & 0 & 0 & 48 & II \\
\hline RIO RUMIYACU & 8 & 6 & 8 & 6 & 5 & 3 & 4 & 2 & 0 & 0 & 0 & 42 & II \\
\hline $\begin{array}{l}\text { LAGUNA NINA } \\
\text { AMARUM } \\
\text { COCHA }\end{array}$ & 10 & 8 & 10 & 8 & 5 & 3 & 4 & 2 & 0 & 0 & 0 & 50 & II \\
\hline SALADEROS & 10 & 8 & 10 & 8 & 5 & 3 & 4 & 2 & 0 & 0 & 0 & 50 & II \\
\hline
\end{tabular}

Los atractivos inventariados y jerarquizados de la comuna Kichwa Mandari Panga se ubica en dos de los cuatro rangos jerárquicos, siendo el Bosque Húmedo Tropical Amazónico del Parque Nacional Yasuní, el único atractivo de Jerarquía IV. Mientras que el resto de atractivos se encuentran en los rangos jerárquicos II y III.

BOSQUE HUMEDO TROPICAL: Luego del análisis el atractivo que ha alcanzado la mayor jerarquía es el Bosque Húmedo Tropical de la comunidad Amazónica Mandaripanga, que por estar ubicado en el parque nacional Yasuni, declarado por la UNESCO, patrimonio natural de la humanidad, toma una gran relevancia no solo a nivel local sino también nacional y mundial.

\section{Trazar sendero, para el desarrollo de las actividades turísticas, recreativas y educativas.}

Finalmente, para definir el diseño de los senderos se realizaron salidas de campo, se utilizó el GPS para determinar las rutas de los senderos y los puntos exactos donde se instalarán los letreros informativos, también se utilizó el programa google earth para realizar el respectivo mapa.

Este sendero tendrá letreros informativos e interpretativos cuyo objetivo será difundir los atractivos de la comuna, serán de gran ayuda para el guía o intérprete ya que con el apoyo de las señales ayudaran a informar y educar a los turistas. En la comuna Kichwa Mandari Panga se desarrollará 
principalmente el turismo comunitario esto permite a los turistas tener más contacto con sus habitantes, conocer las costumbres y el modo de vida de los comuneros.

\section{Tipo de Trazado}

El tipo de trazado para el sendero de la comuna serán lineal es decir tendrán su inicio y el final será diferente.

Se ha diseñado el sendero auto guiado en forma lineal, su diseño sugiere su uso en una sola dirección, lo que permite a los turistas seguir la secuencia de las paradas interpretativas sin tropezar con otros turistas que camina en dirección contraria.

\section{Sendero Mandari Panga}

Grafico 2. Ortofoto del Sendero Turístico Interpretativo de la Comuna Mandari Panga.

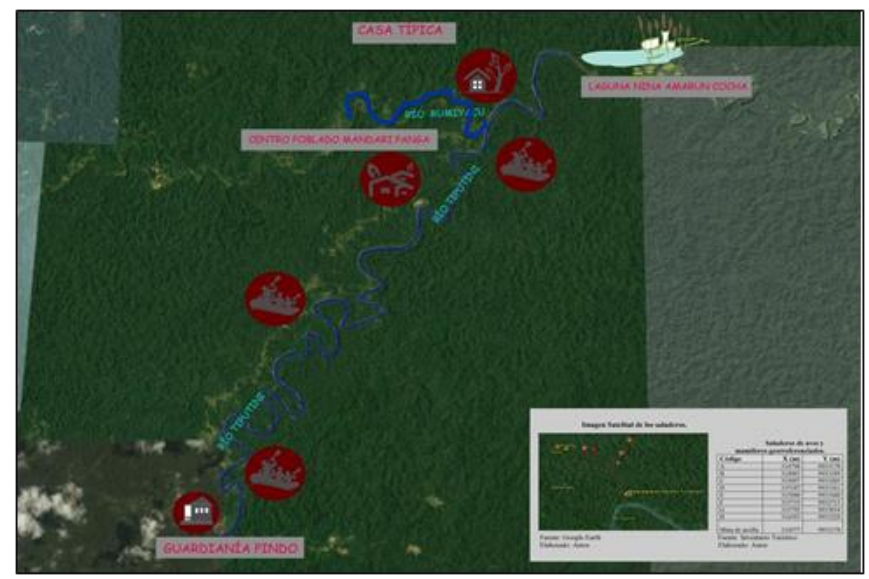

En el gráfico $\mathrm{N}^{\circ} 2$, se puede apreciar la ortofoto del sendero interpretativo de la Comuna Mandari Panga, que posee una longitud de 15220 metros, el tipo de sendero segun el recorrido es lineal, la modalidad interpretativo guiado y se establecio un tiempo de recorrido de tres horas.

Descripción: Este sendero inicia en la guardianía Pindo del Parque Nacional Yasuní, se lo recorrerá en canoa, donde los turistas podrán disfrutar de la belleza escénica del lugar principalmente del Bosque Húmedo Tropical Amazónico ya que es un ecosistema irremplazable y único, que alberga una increíble biodiversidad y que se encuentra entre uno de los más productivos del mundo, igualmente en este sendero los turistas tendrán la oportunidad de ir realizando actividades como observación de flora y fauna tanto en el recorrido por el rio Tiputini como en las caminatas por los atractivos terrestres. 


\section{Diseño de letrero para la comuna Kichwa Mandari Panga}

De acuerdo con la normativa de señalización en Áreas Protegidas (en desarrollo por parte del Ministerio de Ambiente y Turismo) se establece como material para la señalización la madera, se propone utilizar éste material en toda la infraestructura en los senderos. Para los tableros se utilizará madera de pino está sin duda es la mejor alternativa no solamente por las características que tiene sino por la gran capacidad de resistir en la intemperie por largo tiempo.

Los tableros irán sostenidos por caña guadua, está entre las plantas de mayor y más versátil utilización en el mundo, es un organismo ecológicamente sociable y nativo. Los letreros serán realizados en letra Cooper black los títulos y textos en tamaños de acuerdo con el texto de cada señal siempre considerando la fácil legibilidad.

\section{Letrero informativo con croquis de senderos y recomendaciones} Grafico $\mathrm{N}^{\circ}$ 3. Letrero del croquis del Sendero

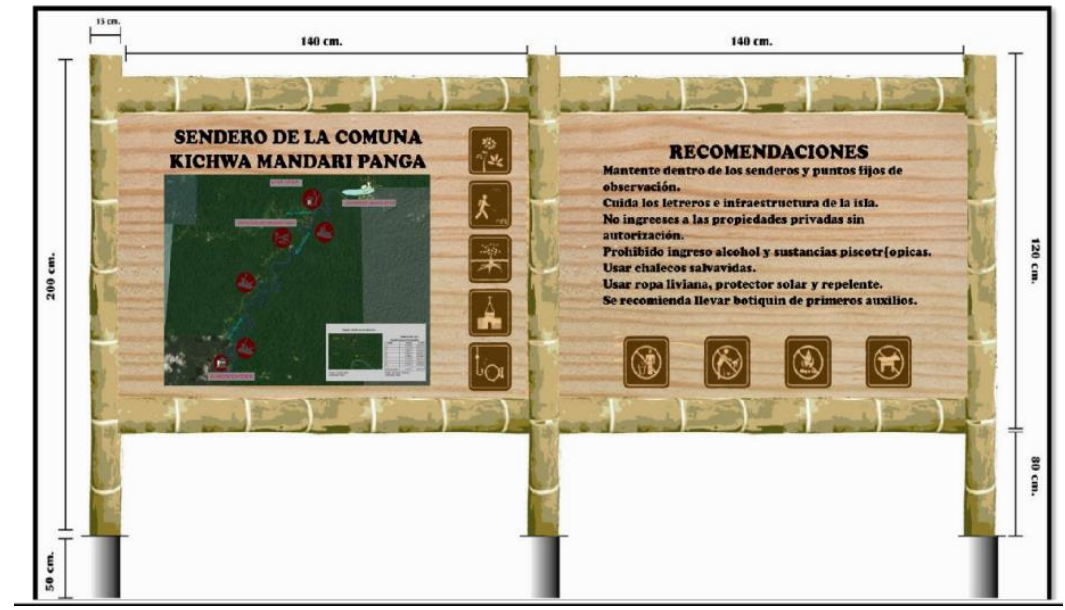

\begin{tabular}{|c|}
\hline Ubicación: En la guardianía de Pindo \\
\hline $\begin{array}{c}\text { Descripción: Es un letrero de dos paneles que se soportan en una estructura formada por tres } \\
\text { postes de caña guadua de } 15 \mathrm{~cm} \text { de diámetro. }\end{array}$ \\
\hline $\begin{array}{c}\text { Materiales: Se utilizara tablones de pino de } 18 \mathrm{~mm} \text { de espesor por } 20 \mathrm{~cm} \text { de ancho, tres postes de } \\
\text { caña guadua, pintura, pernos y tuercas para sostener los tableros. }\end{array}$ \\
\hline $\begin{array}{c}\text { Dimensiones: Las dimensiones de los tableros será de } 140 \mathrm{~cm} \text { de ancho por } 120 \mathrm{~cm} \text { de alto } \\
\text { cada uno. Las dimensiones de la caña guadua serán de } 200 \mathrm{~cm} \text { de alto. Los tableros deberán ser } \\
\text { colocados a } 80 \mathrm{~cm} \text { de alto con respecto al suelo. }\end{array}$ \\
\hline $\begin{array}{c}\text { Tipo y tamaño de letra: El tipo de letra es Cooper black, en color negro la misma que serán } \\
\text { caladas en la madera. El tamaño de las letras será de } 7 \mathrm{~cm} \text { de ancho por } 10 \mathrm{~cm} \text { de alto para los } \\
\text { títulos y de } 5 \mathrm{~cm} \text { de alto por } 3 \mathrm{~cm} \text { de ancho para el contenido secundario. }\end{array}$ \\
\hline $\begin{array}{c}\text { Pictogramas: Calados en el tablero de madera de pino de } 1 \mathrm{~cm} \text { de espesor. Sus medidas serán de } 10 \\
\text { cm de ancho y } 10 \mathrm{~cm} \text { de alto. Recomendable lacar en natural para resaltar la veta de la madera. }\end{array}$ \\
\hline Fotografías: El mapa ira tallado en la madera \\
\hline
\end{tabular}




\section{Letrero informativo sobre la historia de la comuna}

Grafico $\mathrm{N}^{\circ} 4$. Letrero de la historia de la comuna

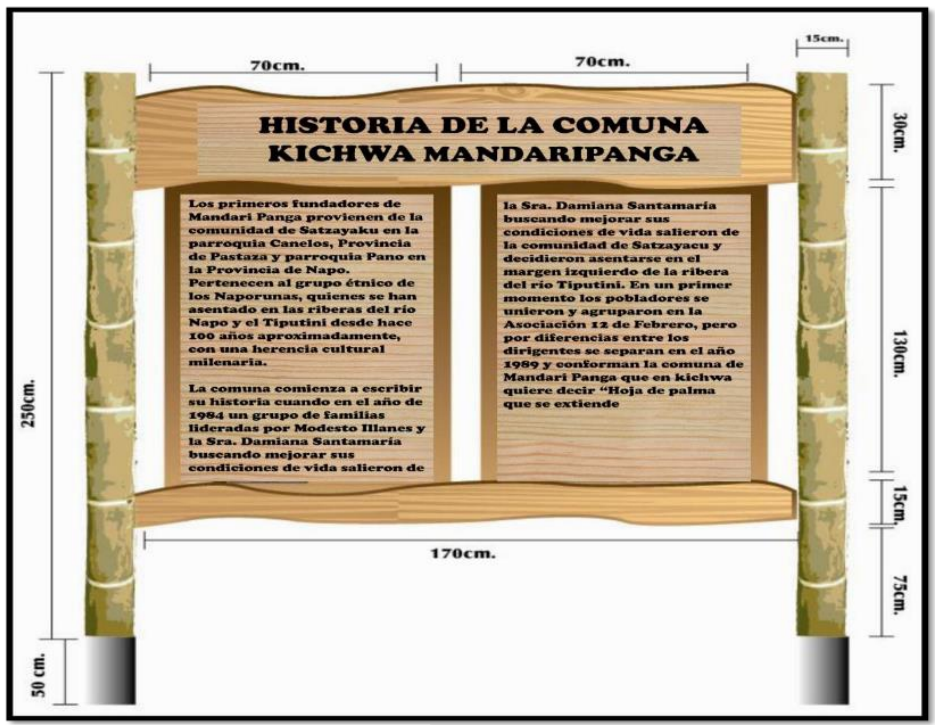

Ubicación: En centro poblado de la Comuna

Descripción: Es un letrero de dos paneles que se soportan en una estructura formada por dos postes de caña de guadua de $15 \mathrm{~cm}$ de diámetro, que sostiene dos tableros en forma horizontal.

Materiales: Se utilizará tablones de pino de $18 \mathrm{~mm}$ de espesor por pernos y turcas para sostener los tableros.

Dimensiones: La dimensión del tablero donde ira el titulo será $170 \mathrm{~cm}$ de ancho por $30 \mathrm{~cm}$ de alto y la dimensión de los tableros donde ira colocada la información será de $70 \mathrm{~cm}$ de ancho por $130 \mathrm{~cm}$ de alto y el tablero superior tendrá una dimensión de $170 \mathrm{~cm}$ de ancho por $15 \mathrm{~cm}$ de alto ubicado a una altura de $75 \mathrm{~cm}$ de alto con respecto al suelo. Los postes de caña guadua tienen una dimensión de $250 \mathrm{~cm}$ de alto.

Tipo y tamaño de letra: El tipo de letra es Cooper black, en color negro la misma que se logrará al momento de calar la madera. El tamaño de la letra para los títulos será de $10 \mathrm{~cm}$ de ancho por $12 \mathrm{~cm}$ de alto y para la información secundaria su tamaño será de $2 \mathrm{~cm}$ de ancho por $5 \mathrm{~cm}$ de alto.

Pictogramas: Calados en el tablero de madera de pino de $1 \mathrm{~cm}$ de espesor. Sus medidas serán de $10 \mathrm{~cm}$ de ancho y $10 \mathrm{~cm}$ de alto. Recomendable lacar en natural para resaltar la veta de la madera. 
2. Letrero informativo de Bosque Húmedo Tropical Amazónico

Grafico $\mathrm{N}^{\circ}$ 5. Letrero del atractivo Bosque Húmedo Tropical Amazónico

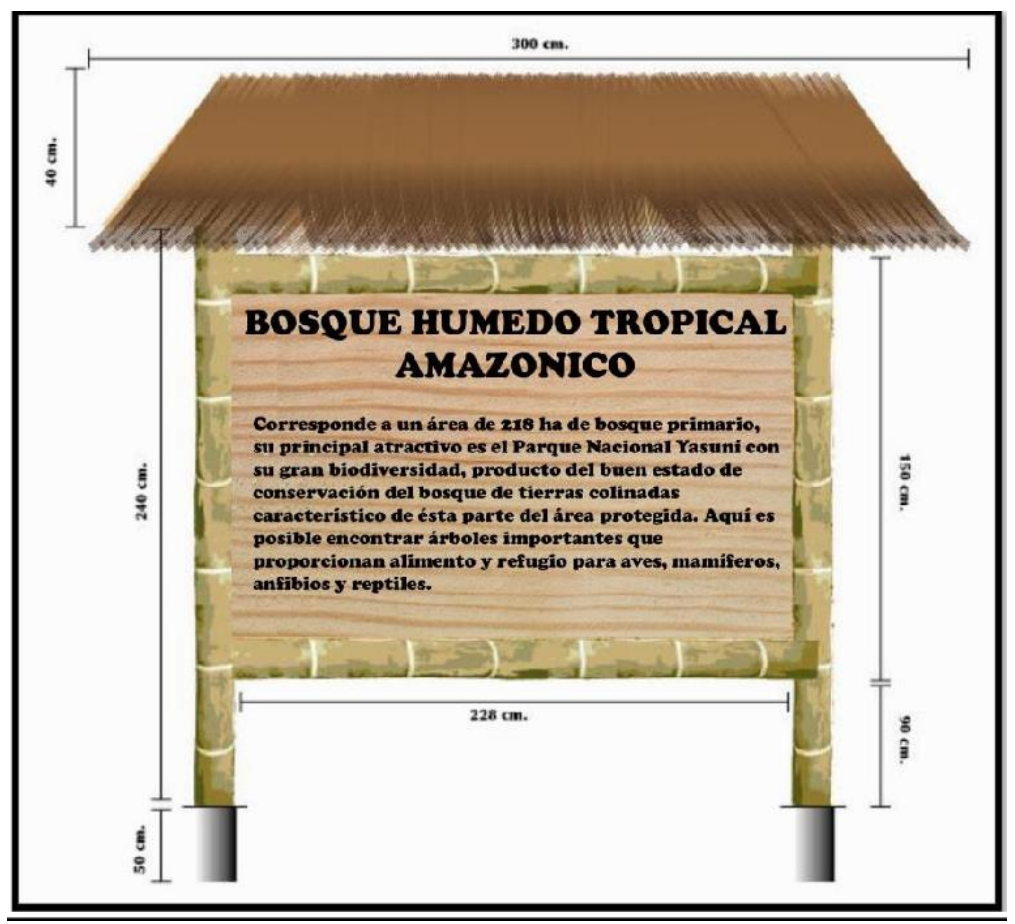

Ubicación: En centro poblado

Descripción: Letrero de un solo panel que se soportará con una estructura formada por dos postes de caña guadua de $15 \mathrm{~cm}$ de diámetro que sostiene un techo.

Materiales: Se utilizará tablones de pinos de $18 \mathrm{~mm}$ de espesor por $20 \mathrm{~cm}$ de ancho, dos postes de caña de guadua, paja, pintura, pernos y turcas para sostener el tablero.

Dimensiones: Las dimensiones del letrero serán de $228 \mathrm{~cm}$ de ancho por $150 \mathrm{~cm}$ de alto. Los postes de caña guadua tendrán $260 \mathrm{~cm}$ de alto. La altura en la que deberá estar colocado el letrero será a una dimensión de $90 \mathrm{~cm}$ de alto con respecto al suelo.

Tipo y tamaño de letra: El tipo de letra que se utilizará es Cooper black color negro. El tamaño para los títulos será de $10 \mathrm{~cm} \times 10 \mathrm{~cm}$ y para el contenido secundario su tamaño será de $5 \mathrm{~cm}$ x $5 \mathrm{~cm}$. Los logotipos tendrán un tamaño de $10 \mathrm{~cm}$ de ancho x $10 \mathrm{~cm} \mathrm{de}$ alto. 
3. Letrero informativo sobre El río Tiputini

Grafico $\mathrm{N}^{\circ}$ 6. Letrero del Rio Tiputini

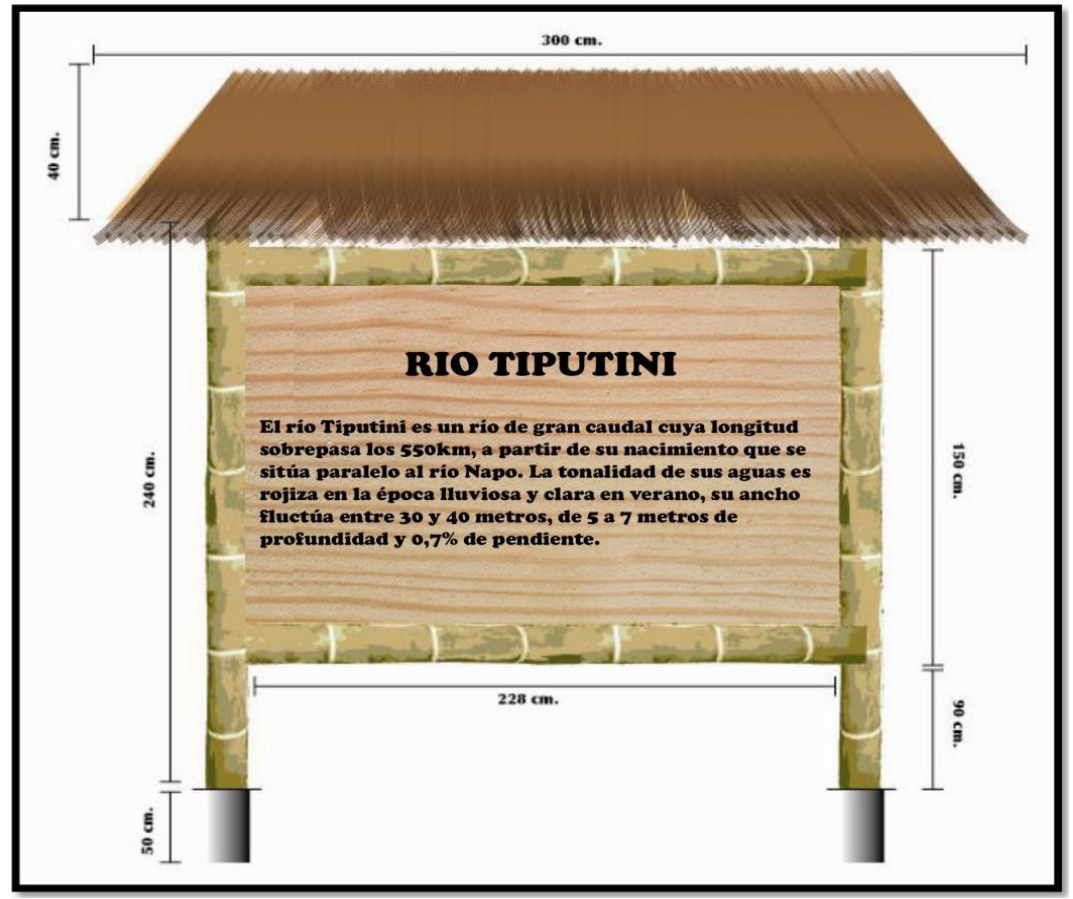

Ubicación: En la guardianía de Pindo

Descripción: Letrero de un solo panel que se soportará con una estructura formada por dos postes de caña guadua de $15 \mathrm{~cm}$ de diámetro que sostiene un techo.

Materiales: Se utilizará tablones de pinos de $18 \mathrm{~mm}$ de espesor por $20 \mathrm{~cm}$ de ancho, dos postes de caña de guadua, paja, pintura, pernos y turcas para sostener el tablero.

Dimensiones: Las dimensiones del letrero serán de $228 \mathrm{~cm}$ de ancho por $150 \mathrm{~cm}$ de alto. Los postes de caña guadua tendrán $260 \mathrm{~cm}$ de alto. La altura en la que deberá estar colocado el letrero será a una dimensión de $90 \mathrm{~cm}$ de alto con respecto al suelo.

Tipo y tamaño de letra: El tipo de letra que se utilizará es Cooper black color negro. El tamaño para los títulos será de $10 \mathrm{~cm} \times 10 \mathrm{~cm}$ y para el contenido secundario su tamaño será de $5 \mathrm{~cm} \times 5 \mathrm{~cm}$. Los logotipos tendrán un tamaño de $10 \mathrm{~cm}$ de ancho x $10 \mathrm{~cm}$ de alto. 


\section{Letrero informativo sobre El río Rumiyacu}

Grafico $\mathrm{N}^{\circ}$ 7. Letrero del Rio Rumiyacu

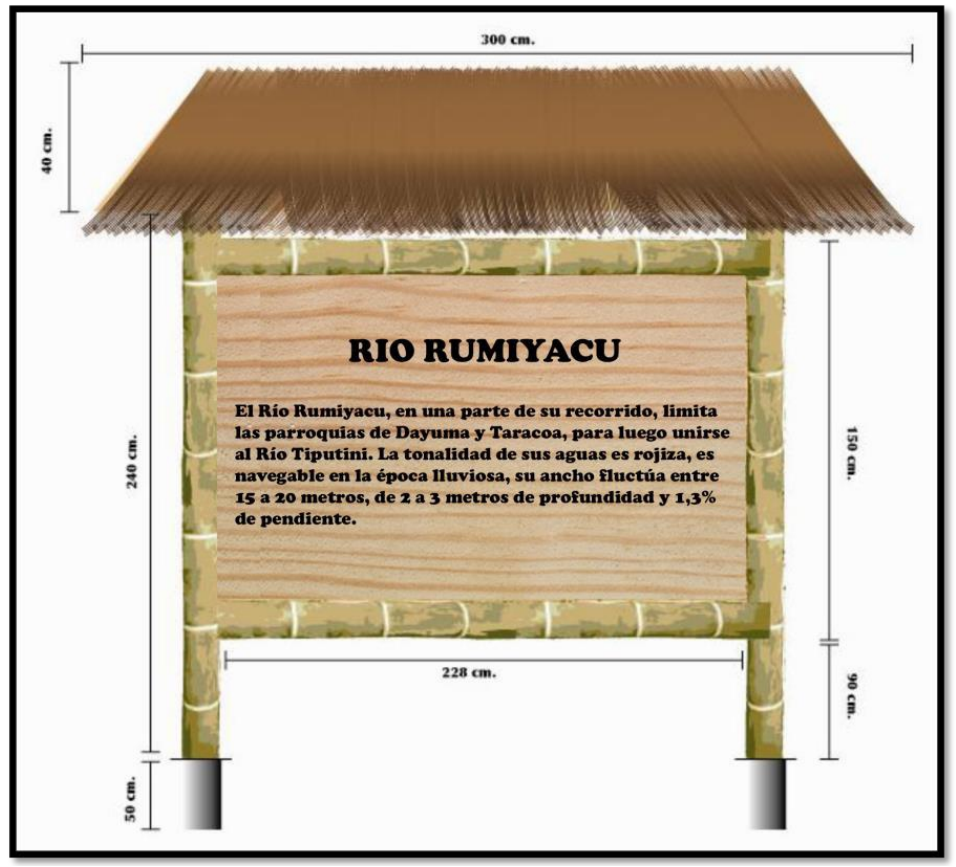

Ubicación: En intersección del Rio Rumiyacu y Tiputini

Descripción: Letrero de un solo panel que se soportará con una estructura

formada por dos postes de caña guadua de $15 \mathrm{~cm}$ de diámetro que sostiene un techo.

Materiales: Se utilizará tablones de pinos de $18 \mathrm{~mm}$ de espesor por $20 \mathrm{~cm}$ de ancho, dos postes de caña de guadua, paja, pintura, pernos y turcas para sostener el tablero.

Dimensiones: Las dimensiones del letrero serán de $228 \mathrm{~cm}$ de ancho por $150 \mathrm{~cm}$ de alto. Los postes de caña guadua tendrán $260 \mathrm{~cm}$ de alto. La altura en la que deberá estar colocado el letrero será a una dimensión de $90 \mathrm{~cm}$ de alto con respecto al suelo. Tipo y tamaño de letra: El tipo de letra que se utilizará es Cooper black color negro. El tamaño para los títulos será de $10 \mathrm{~cm}$ x $10 \mathrm{~cm}$ y para el contenido secundario su tamaño será de $5 \mathrm{~cm} \times 5 \mathrm{~cm}$. Los logotipos tendrán un tamaño de $10 \mathrm{~cm}$ de ancho $\mathrm{x} 10 \mathrm{~cm}$ de alto. 


\section{Letrero informativo de los saladeros}

Gráfico 8. Letrero Informativo de los Saladeros

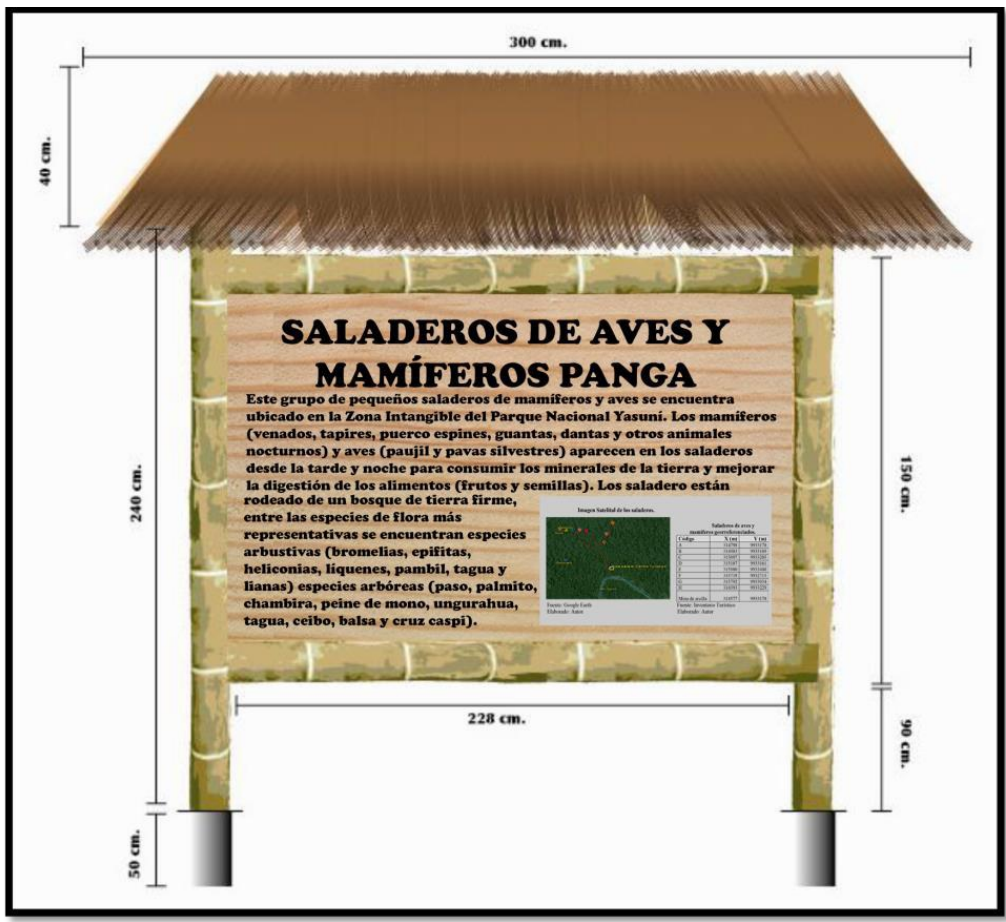

Ubicación: Saladeros de aves y mamíferos

Descripción: Letrero de un solo panel que se soportará con una estructura formada por dos postes de caña guadua de $15 \mathrm{~cm}$ de diámetro que sostiene un techo.

Materiales: Se utilizará tablones de pinos de $18 \mathrm{~mm}$ de espesor por $20 \mathrm{~cm}$ de ancho, dos postes de caña de guadua, paja, pintura, pernos y turcas para sostener el tablero.

Dimensiones: Las dimensiones del letrero serán de $228 \mathrm{~cm}$ de ancho por $150 \mathrm{~cm}$ de alto. Los postes de caña guadua tendrán $260 \mathrm{~cm}$ de alto. La altura en la que deberá estar colocado el letrero será a una dimensión de $90 \mathrm{~cm}$ de alto con respecto al suelo.

Tipo y tamaño de letra: El tipo de letra que se utilizará es Cooper black color negro. El tamaño para los títulos será de $10 \mathrm{~cm}$ x $10 \mathrm{~cm}$ y para el contenido secundario su tamaño será de $5 \mathrm{~cm}$ x $5 \mathrm{~cm}$. Los logotipos tendrán un tamaño de $10 \mathrm{~cm}$ de ancho x $10 \mathrm{~cm}$ de alto. 
a. Letrero informativo del saladero $A$

Grafico $\mathrm{N}^{\circ}$ 9. Letrero del saladero A

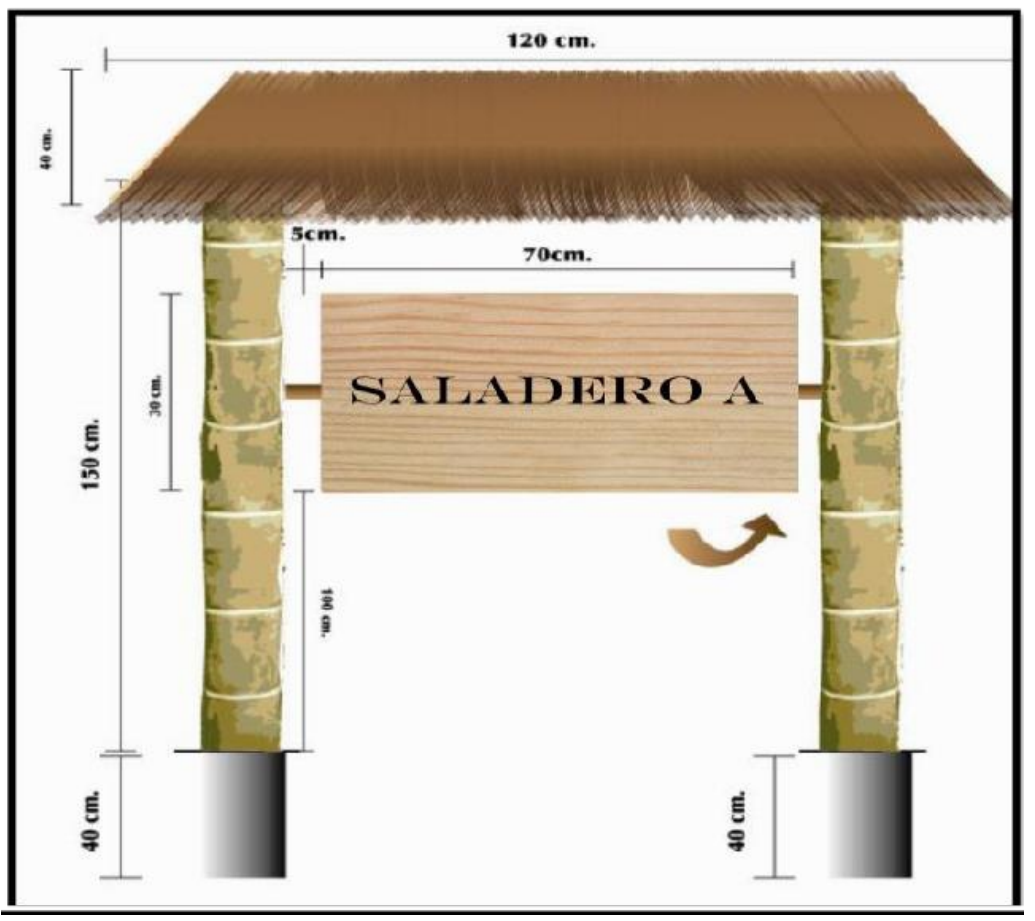

Ubicación: X(m) 314798

Descripción: Es un letrero de solo panel que se soporta en una estructura formada por dos postes de caña guadua de $15 \mathrm{~cm}$ de diámetro, que sostiene un techo.

Materiales: Se utilizará tablones de pino de $18 \mathrm{~mm}$ de espesor por $20 \mathrm{~cm}$ de ancho, dos postes de caña guadua, dos palatinas de media con perno para que el tablero pueda girar fácilmente, pintura, paja y clavos

Dimensiones: La dimensión del tablero será de $70 \mathrm{~cm}$ de ancho por $30 \mathrm{~cm}$ de alto. Los postes de caña guadua tendrán una dimensión de $150 \mathrm{~cm}$ de alto. El tablero estará a una altura de $100 \mathrm{~cm}$ de alto con respecto al suelo.

Tipo y tamaño de letra: El tipo de letra es Cooper black, en color negro la misma que se logrará al momento de calar la madera. El tamaño de la letra será de $3 \mathrm{~cm}$ de ancho por $6 \mathrm{~cm}$ de alto para la pregunta y para la respuesta será de $2 \mathrm{~cm}$ de ancho por $6 \mathrm{~cm}$ de alto. 
b. $\quad$ Letrero informativo del saladero B

Grafico $\mathrm{N}^{\circ} 10$. Letrero del saladero B

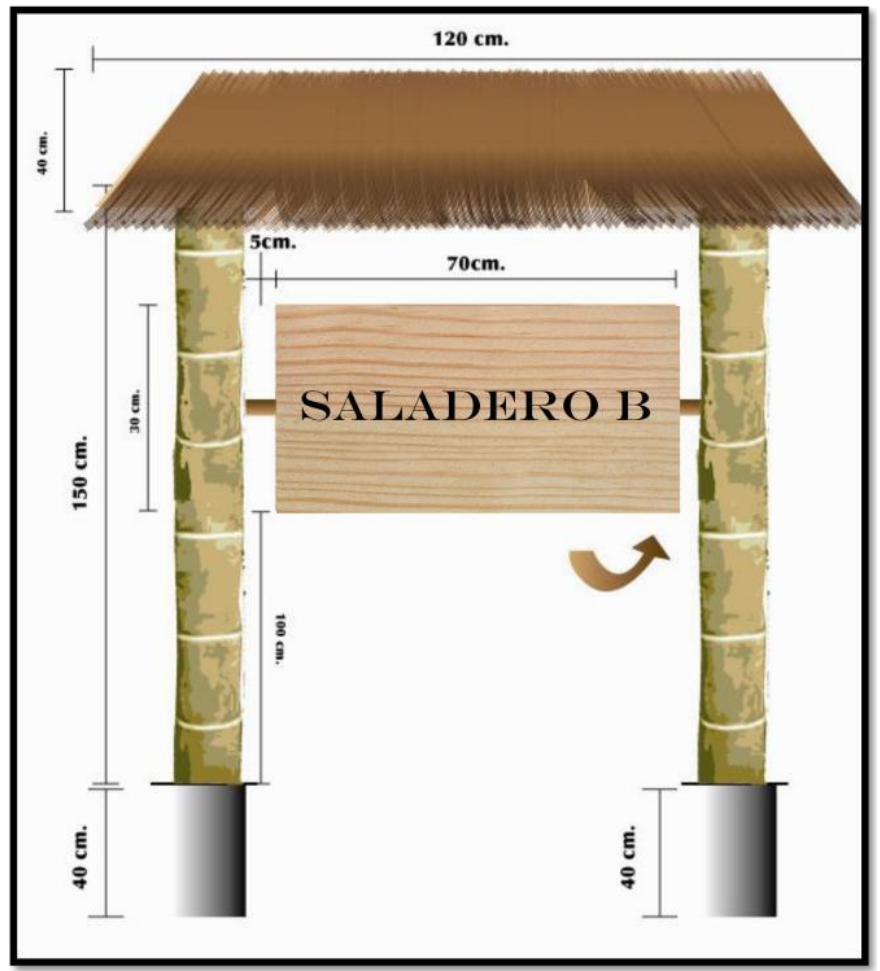

\section{Ubicación: X(m) 314983}

Descripción: Es un letrero de solo panel que se soporta en una estructura formada por dos postes de caña guadua de $15 \mathrm{~cm}$ de diámetro, que sostiene un techo.

Materiales: Se utilizará tablones de pino de $18 \mathrm{~mm}$ de espesor por $20 \mathrm{~cm}$ de ancho, dos postes de caña guadua, dos palatinas de media con perno para que el tablero pueda girar fácilmente, pintura, paja y clavos

Dimensiones: La dimensión del tablero será de $70 \mathrm{~cm}$ de ancho por $30 \mathrm{~cm}$ de alto. Los postes de caña guadua tendrán una dimensión de $150 \mathrm{~cm}$ de alto. El tablero estará a una altura de $100 \mathrm{~cm}$ de alto con respecto al suelo.

Tipo y tamaño de letra: El tipo de letra es Cooper black, en color negro la misma que se logrará al momento de calar la madera. El tamaño de la letra será de $3 \mathrm{~cm}$ de ancho por $6 \mathrm{~cm}$ de alto para la pregunta y para la respuesta será de $2 \mathrm{~cm}$ de ancho por $6 \mathrm{~cm}$ de alto. 
c. Letrero informativo del saladero $\mathbf{C}$

Grafico $\mathrm{N}^{\circ} 11$. Letrero del saladero

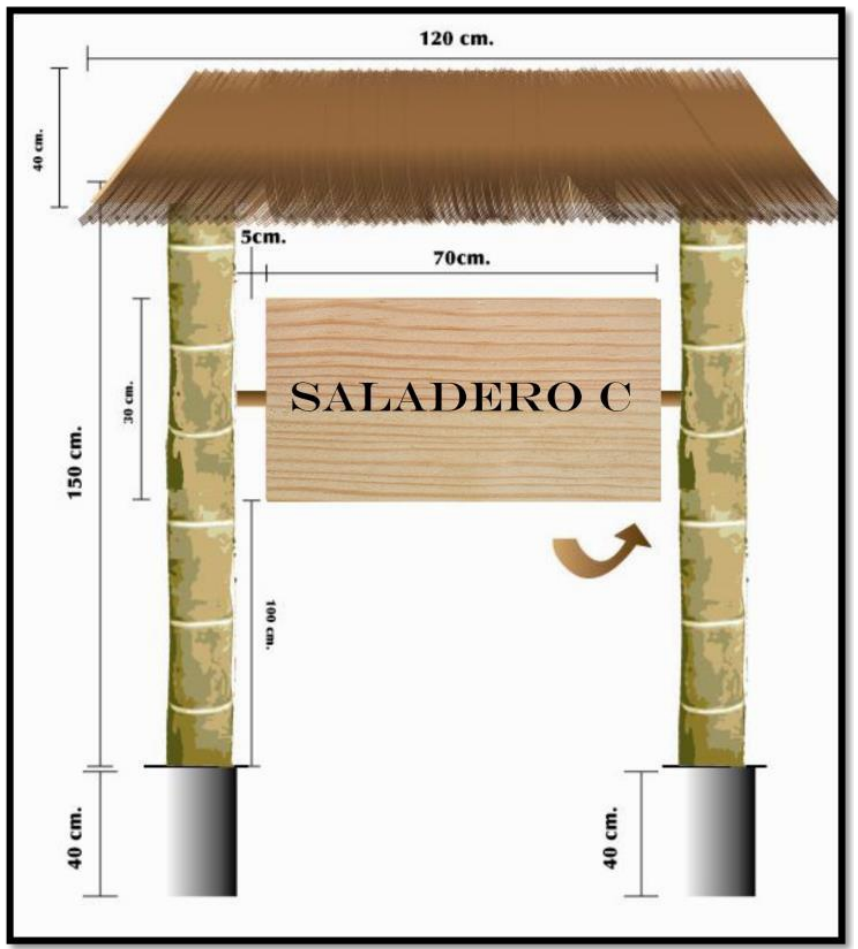

Ubicación: X(m) 315097

Descripción: Es un letrero de solo panel que se soporta en una estructura formada por dos postes de caña guadua de $15 \mathrm{~cm}$ de diámetro, que sostiene un techo.

Materiales: Se utilizará tablones de pino de $18 \mathrm{~mm}$ de espesor por $20 \mathrm{~cm}$ de ancho, dos postes de caña guadua, dos palatinas de media con perno para que el tablero pueda girar fácilmente, pintura, paja y clavos

Dimensiones: La dimensión del tablero será de $70 \mathrm{~cm}$ de ancho por $30 \mathrm{~cm}$ de alto. Los postes de caña guadua tendrán una dimensión de $150 \mathrm{~cm}$ de alto. El tablero estará a una altura de $100 \mathrm{~cm}$ de alto con respecto al suelo.

Tipo y tamaño de letra: El tipo de letra es Cooper black, en color negro la misma que se logrará al momento de calar la madera. El tamaño de la letra será de $3 \mathrm{~cm}$ de ancho por $6 \mathrm{~cm}$ de alto para la pregunta y para la respuesta será de $2 \mathrm{~cm}$ de ancho por $6 \mathrm{~cm}$ de alto. 


\section{d. $\quad$ Letrero informativo del saladero D}

Grafico $\mathrm{N}^{\circ} 12$. Letrero del saladero D

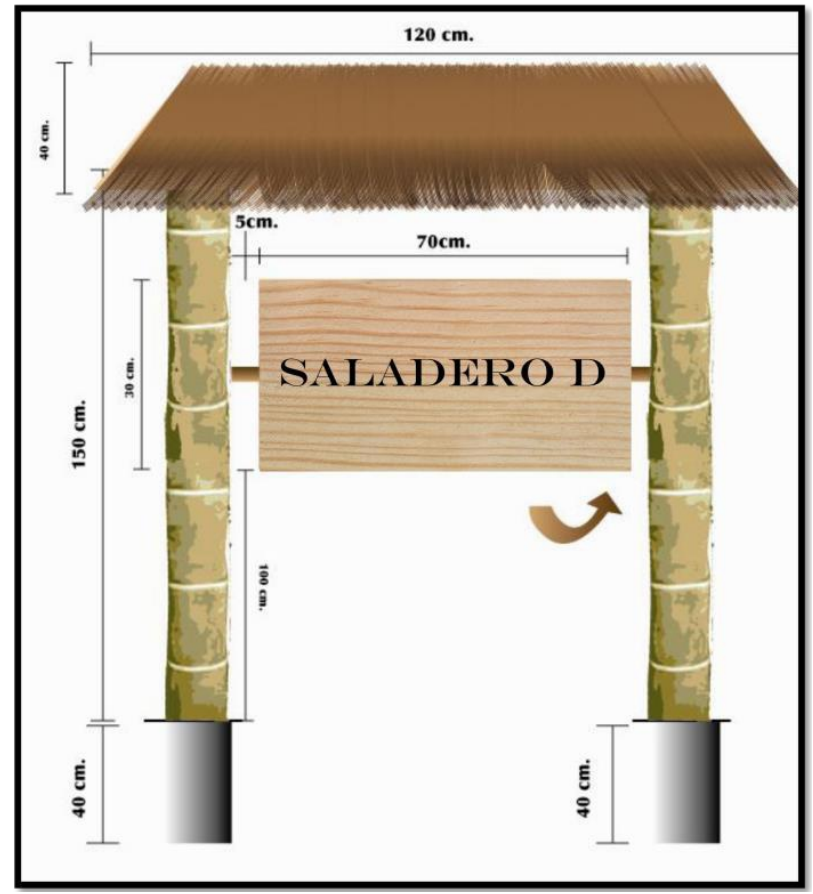

\section{Ubicación: X(m) 315187}

Descripción: Es un letrero de solo panel que se soporta en una estructura formada por dos postes de caña guadua de $15 \mathrm{~cm}$ de diámetro, que sostiene un techo.

Materiales: Se utilizará tablones de pino de $18 \mathrm{~mm}$ de espesor por $20 \mathrm{~cm}$ de ancho, dos postes de caña guadua, dos palatinas de media con perno para que el tablero pueda girar fácilmente, pintura, paja y clavos

Dimensiones: La dimensión del tablero será de $70 \mathrm{~cm}$ de ancho por $30 \mathrm{~cm}$ de alto. Los postes de caña guadua tendrán una dimensión de $150 \mathrm{~cm}$ de alto. El tablero estará a una altura de $100 \mathrm{~cm}$ de alto con respecto al suelo.

Tipo y tamaño de letra: El tipo de letra es Cooper black, en color negro la misma que se logrará al momento de calar la madera. El tamaño de la letra será de $3 \mathrm{~cm}$ de ancho por $6 \mathrm{~cm}$ de alto para la pregunta y para la respuesta será de $2 \mathrm{~cm}$ de ancho por $6 \mathrm{~cm}$ de alto. 
e. Letrero informativo del saladero $\mathbf{E}$

Gráfico $\mathrm{N}^{\circ}$ 13.Letrero del saladero $\mathrm{E}$

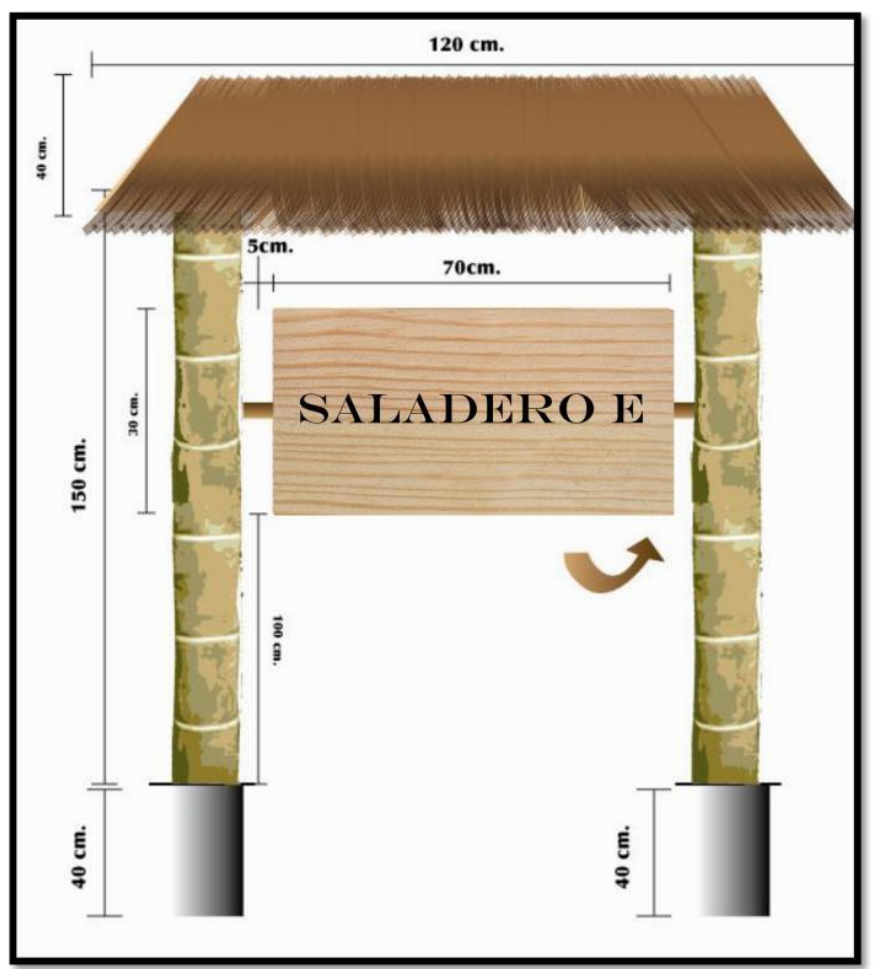

\section{Ubicación: X(m) 315980}

Descripción: Es un letrero de solo panel que se soporta en una estructura formada por dos postes de caña guadua de $15 \mathrm{~cm}$ de diámetro, que sostiene un techo.

Materiales: Se utilizará tablones de pino de $18 \mathrm{~mm}$ de espesor por $20 \mathrm{~cm}$ de ancho, dos postes de caña guadua, dos palatinas de media con perno para que el tablero pueda girar fácilmente, pintura, paja y clavos

Dimensiones: La dimensión del tablero será de $70 \mathrm{~cm}$ de ancho por $30 \mathrm{~cm}$ de alto. Los postes de caña guadua tendrán una dimensión de $150 \mathrm{~cm}$ de alto. El tablero estará a una altura de $100 \mathrm{~cm}$ de alto con respecto al suelo.

Tipo y tamaño de letra: El tipo de letra es Cooper black, en color negro la misma que se logrará al momento de calar la madera. El tamaño de la letra será de $3 \mathrm{~cm}$ de ancho por $6 \mathrm{~cm}$ de alto para la pregunta y para la respuesta será de $2 \mathrm{~cm}$ de ancho por $6 \mathrm{~cm}$ de alto. 


\section{f. Letrero informativo del saladero $\mathbf{F}$}

$$
\text { Grafico } \mathrm{N}^{\circ} 14 \text {. Letrero del saladero } \mathrm{F}
$$

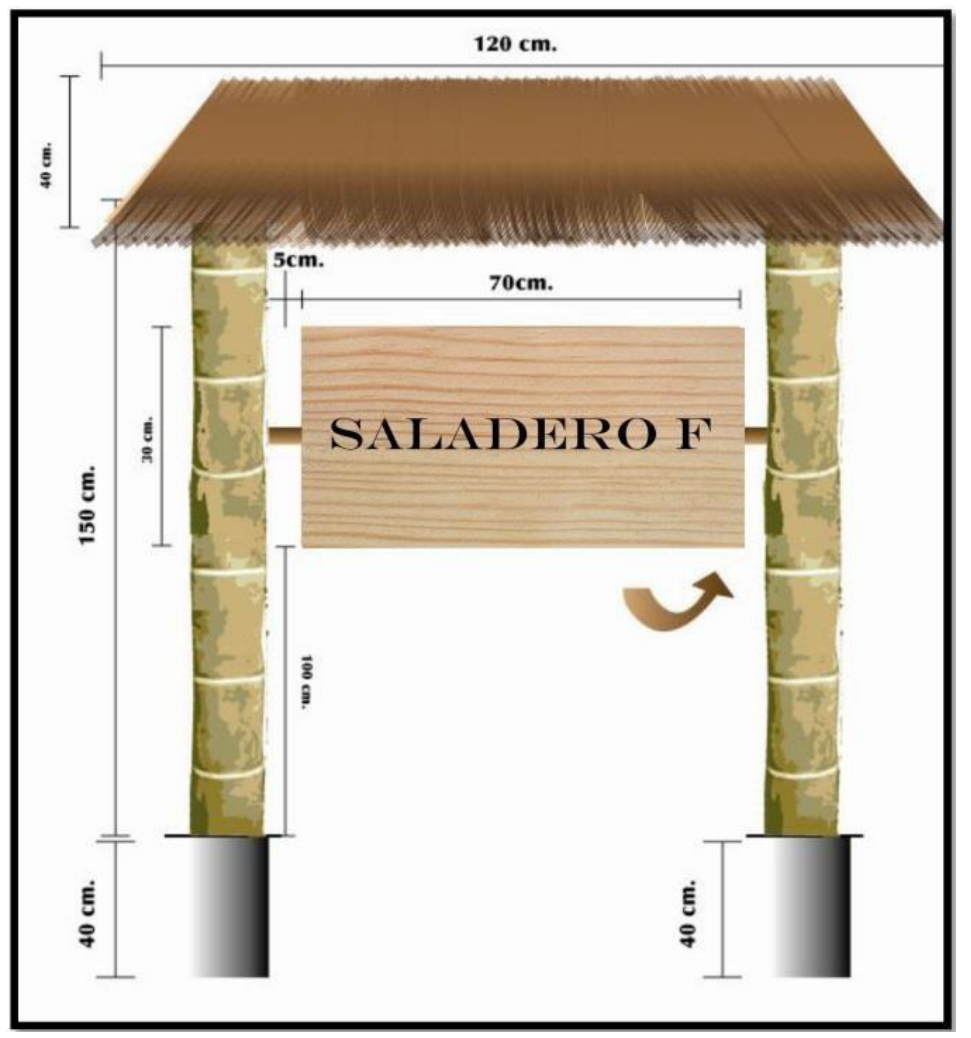

\section{Ubicación: X(m) 315719}

Descripción: Es un letrero de solo panel que se soporta en una estructura formada por dos postes de caña guadua de $15 \mathrm{~cm}$ de diámetro, que sostiene un techo.

Materiales: Se utilizará tablones de pino de $18 \mathrm{~mm}$ de espesor por $20 \mathrm{~cm}$ de ancho, dos postes de caña guadua, dos palatinas de media con perno para que el tablero pueda girar fácilmente, pintura, paja y clavos

Dimensiones: La dimensión del tablero será de $70 \mathrm{~cm}$ de ancho por $30 \mathrm{~cm}$ de alto. Los postes de caña guadua tendrán una dimensión de $150 \mathrm{~cm}$ de alto. El tablero estará a una altura de $100 \mathrm{~cm}$ de alto con respecto al suelo.

Tipo y tamaño de letra: El tipo de letra es Cooper black, en color negro la misma que se logrará al momento de calar la madera. El tamaño de la letra será de $3 \mathrm{~cm}$ de ancho por $6 \mathrm{~cm}$ de alto para la pregunta y para la respuesta será de $2 \mathrm{~cm}$ de ancho por $6 \mathrm{~cm}$ de alto. 


\section{g. Letrero informativo del saladero G}

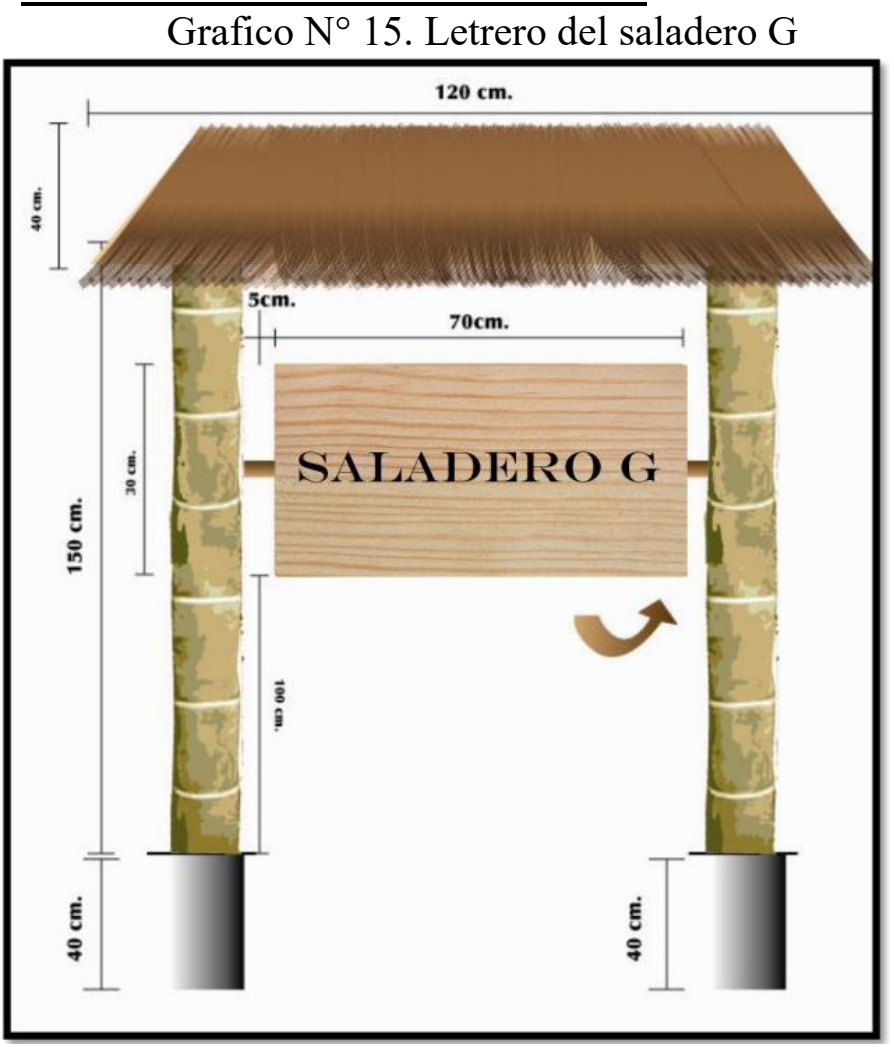

\section{Ubicación: X(m) 315792}

Descripción: Es un letrero de solo panel que se soporta en una estructura formada por dos postes de caña guadua de $15 \mathrm{~cm}$ de diámetro, que sostiene un techo.

Materiales: Se utilizará tablones de pino de $18 \mathrm{~mm}$ de espesor por $20 \mathrm{~cm}$ de ancho, dos postes de caña guadua, dos palatinas de media con perno para que el tablero pueda girar fácilmente, pintura, paja y clavos

Dimensiones: La dimensión del tablero será de $70 \mathrm{~cm}$ de ancho por $30 \mathrm{~cm}$ de alto. Los postes de caña guadua tendrán una dimensión de $150 \mathrm{~cm}$ de alto. El tablero estará a una altura de $100 \mathrm{~cm}$ de alto con respecto al suelo.

Tipo y tamaño de letra: El tipo de letra es Cooper black, en color negro la misma que se logrará al momento de calar la madera. El tamaño de la letra será de $3 \mathrm{~cm}$ de ancho por $6 \mathrm{~cm}$ de alto para la pregunta y para la respuesta será de $2 \mathrm{~cm}$ de ancho por $6 \mathrm{~cm}$ de alto. 
h. Letrero informativo del saladero $\mathbf{H}$

Grafico $\mathrm{N}^{\circ} 16$. Letrero del saladero $\mathrm{H}$

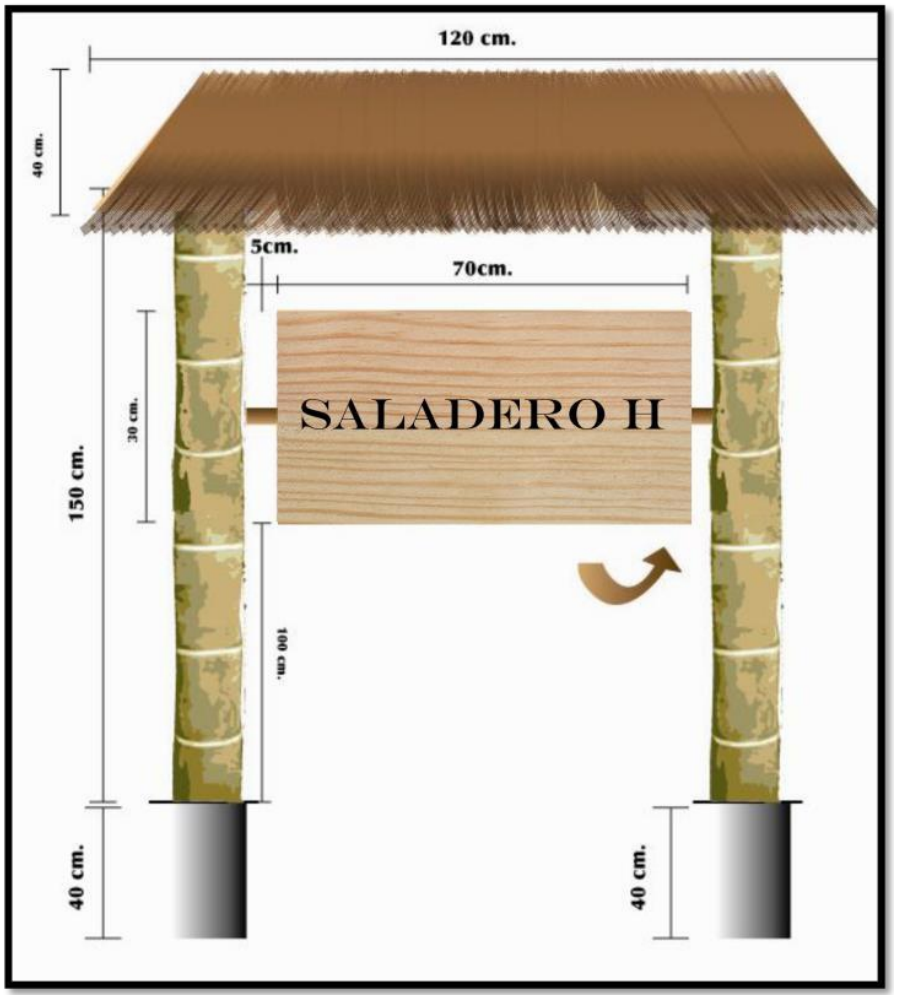

Ubicación: X(m) 314393

Descripción: Es un letrero de solo panel que se soporta en una estructura formada por dos postes de caña guadua de $15 \mathrm{~cm}$ de diámetro, que sostiene un techo.

Materiales: Se utilizará tablones de pino de $18 \mathrm{~mm}$ de espesor por $20 \mathrm{~cm}$ de ancho, dos postes de caña guadua, dos palatinas de media con perno para que el tablero pueda girar fácilmente, pintura, paja y clavos

Dimensiones: La dimensión del tablero será de $70 \mathrm{~cm}$ de ancho por $30 \mathrm{~cm}$ de alto. Los postes de caña guadua tendrán una dimensión de $150 \mathrm{~cm}$ de alto. El tablero estará a una altura de $100 \mathrm{~cm}$ de alto con respecto al suelo.

Tipo y tamaño de letra: El tipo de letra es Cooper black, en color negro la misma que se logrará al momento de calar la madera. El tamaño de la letra será de $3 \mathrm{~cm}$ de ancho por $6 \mathrm{~cm}$ de alto para la pregunta y para la respuesta será de $2 \mathrm{~cm}$ de ancho por $6 \mathrm{~cm}$ de alto. 
6. Letrero informativo de la Laguna Nina Amarun Choca. Grafico $N^{\circ} 17$. Letrero de la Laguna Nina Amarun Cocha

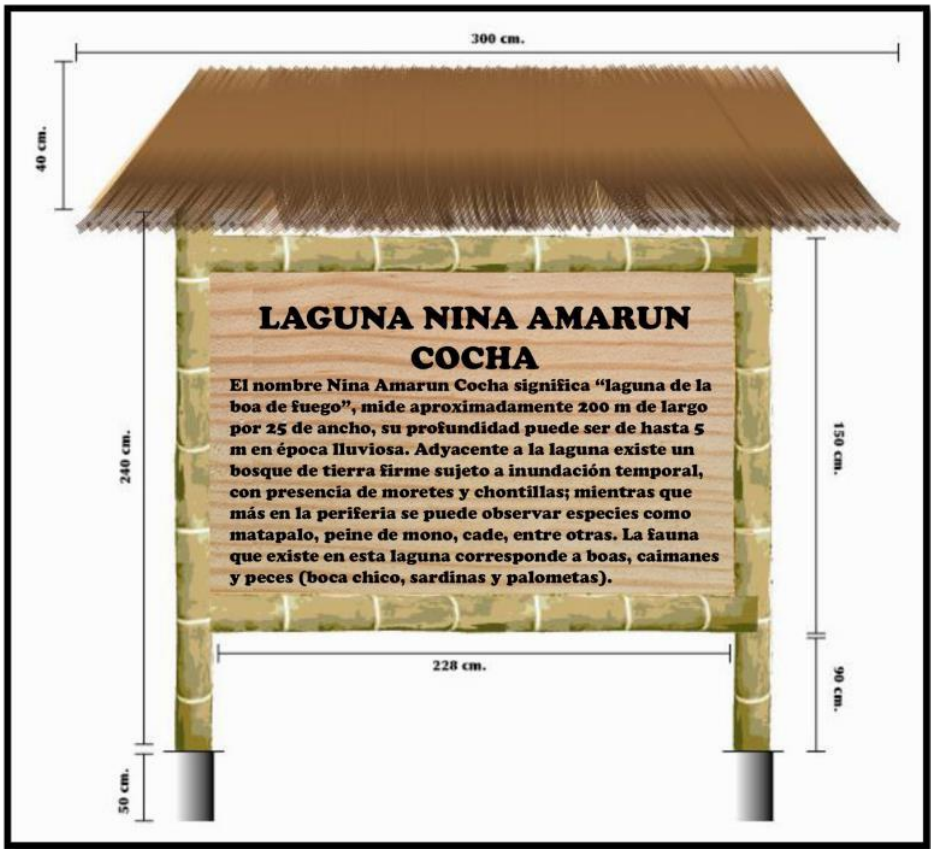

Ubicación: En la entra de la laguna.

Descripción: Letrero de un solo panel que se soportará con una estructura formada por dos postes de caña guadua de $15 \mathrm{~cm}$ de diámetro que sostiene un techo.

Materiales: Se utilizará tablones de pinos de $18 \mathrm{~mm}$ de espesor por $20 \mathrm{~cm}$ de ancho, dos postes de caña de guadua, paja, pintura, pernos y turcas para sostener el tablero.

Dimensiones: Las dimensiones del letrero serán de $228 \mathrm{~cm}$ de ancho por $150 \mathrm{~cm}$ de alto. Los postes de caña guadua tendrán $260 \mathrm{~cm}$ de alto. La altura en la que deberá estar colocado el letrero será a una dimensión de $90 \mathrm{~cm}$ de alto con respecto al suelo.

Tipo y tamaño de letra: El tipo de letra que se utilizará es Cooper black color negro. El tamaño para los títulos será de $10 \mathrm{~cm}$ x $10 \mathrm{~cm}$ y para el contenido secundario su tamaño será de $5 \mathrm{~cm}$ x $5 \mathrm{~cm}$. Los logotipos tendrán un tamaño de $10 \mathrm{~cm}$ de ancho x $10 \mathrm{~cm}$ de alto. 


\section{Letrero informativo de la casa típica}

Grafico $\mathrm{N}^{\circ} 18$. Letrero de la casa típica

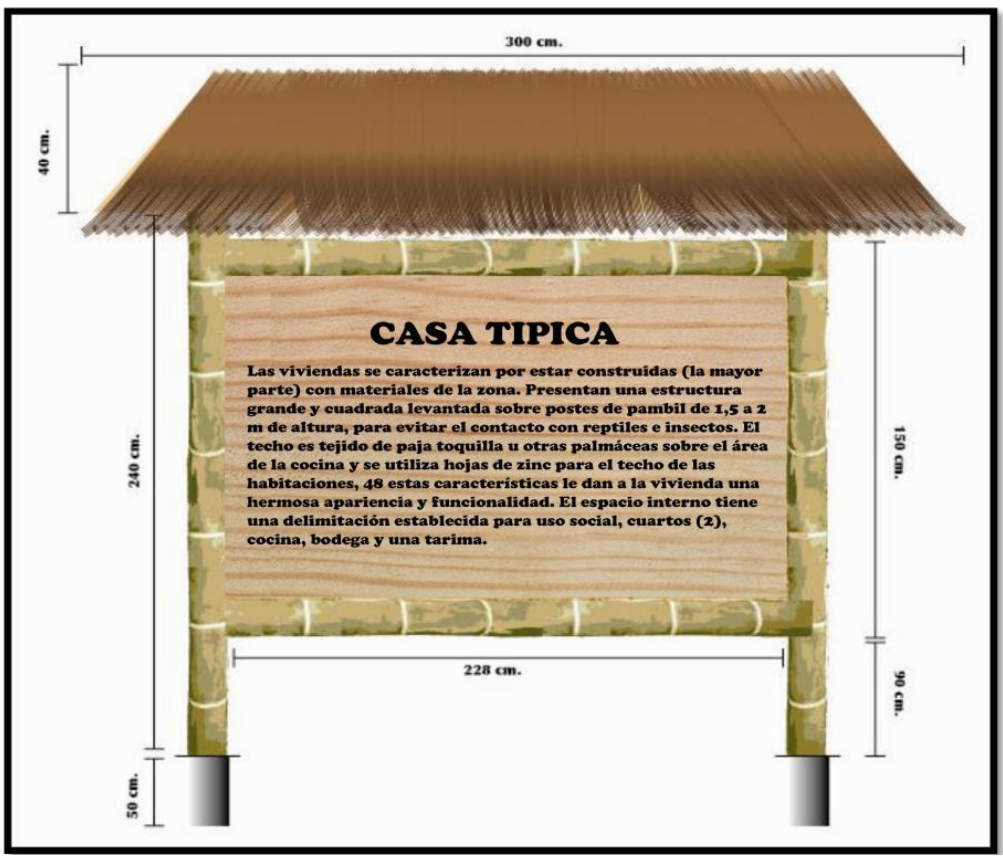

Ubicación: En la casa típica

Descripción: Letrero de un solo panel que se soportará con una estructura formada por dos postes de caña guadua de $15 \mathrm{~cm}$ de diámetro que sostiene un techo.

Materiales: Se utilizará tablones de pinos de $18 \mathrm{~mm}$ de espesor por $20 \mathrm{~cm}$ de ancho, dos postes de caña de guadua, paja, pintura, pernos y turcas para sostener el tablero.

Dimensiones: Las dimensiones del letrero serán de $228 \mathrm{~cm}$ de ancho por $150 \mathrm{~cm}$ de alto. Los postes de caña guadua tendrán $260 \mathrm{~cm}$ de alto. La altura en la que deberá estar colocado el letrero será a una dimensión de $90 \mathrm{~cm}$ de alto con respecto al suelo.

Tipo y tamaño de letra: El tipo de letra que se utilizará es Cooper black color negro. El tamaño para los títulos será de $10 \mathrm{~cm} \times 10 \mathrm{~cm}$ y para el contenido secundario su tamaño será de $5 \mathrm{~cm} \times 5 \mathrm{~cm}$. Los logotipos tendrán un tamaño de $10 \mathrm{~cm}$ de ancho x $10 \mathrm{~cm}$ de alto. 
8. Letrero historia de la comuna

Gráfico $\mathrm{N}^{\circ} 19$. Historia de la Comuna

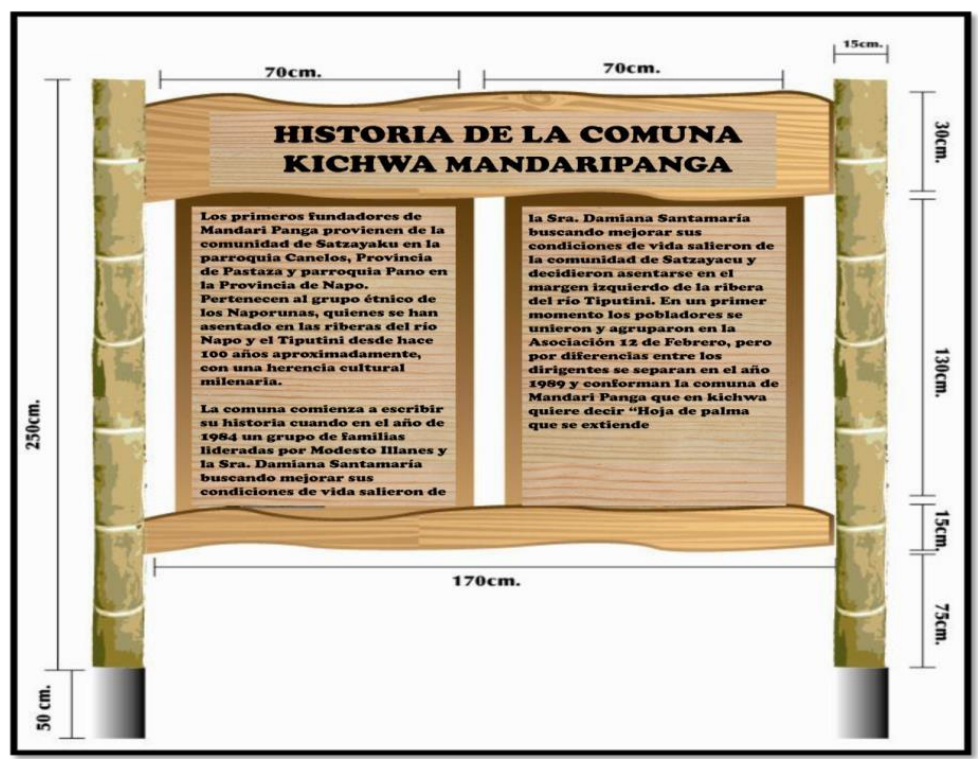

\section{Letrero para los atractivos}

Gráfico $\mathrm{N}^{\circ} 20$. Letrero Atractivos de La Comuna

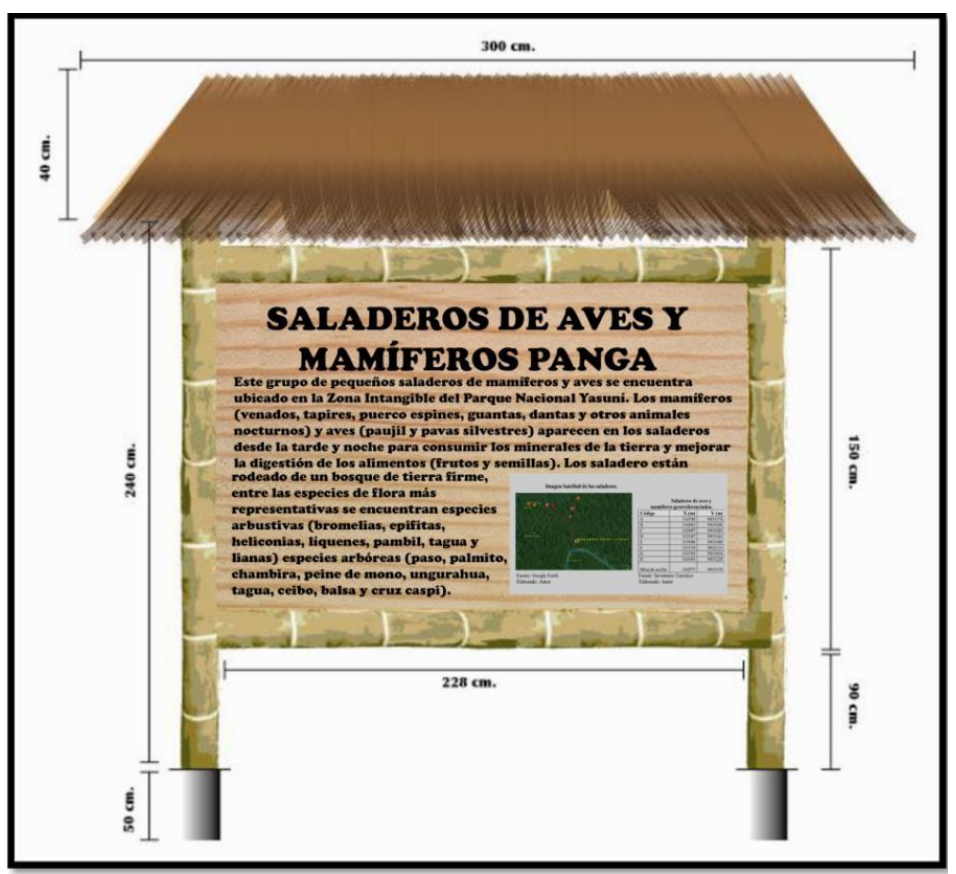




\section{Letrero de los saladeros}

Gráfico $\mathrm{N}^{\circ} 21$. Saladero $\mathrm{F}$

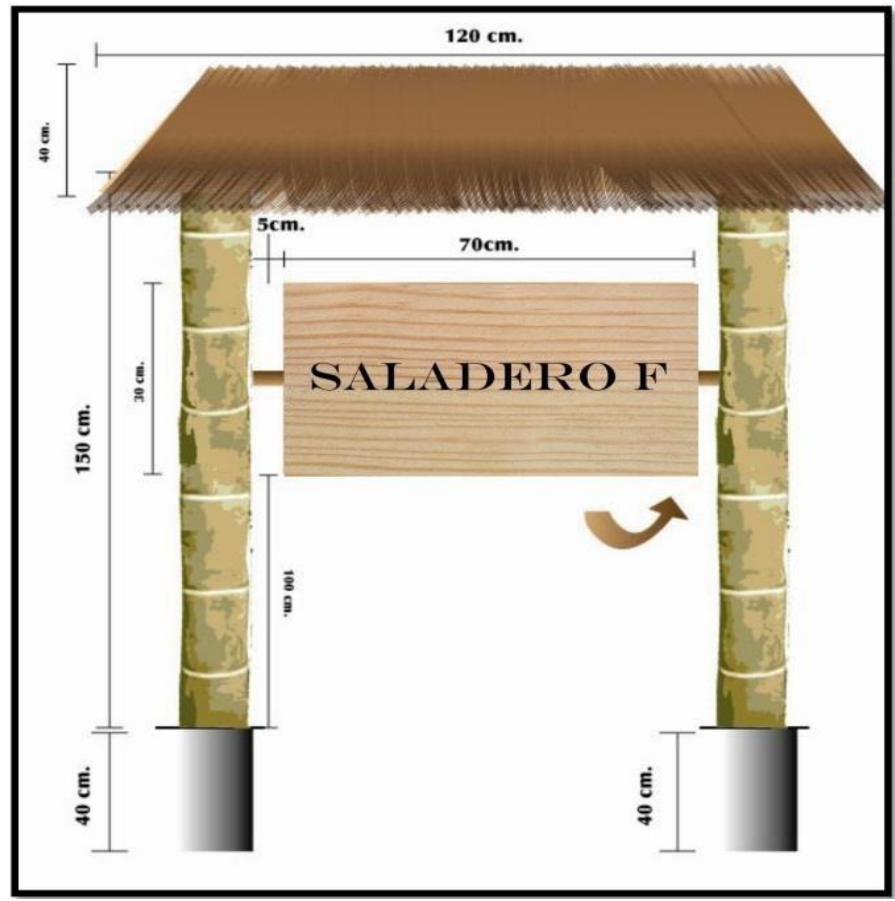

\section{Conclusion:}

La comuna kichwa Mandari Panga posee una gran diversidad de atractivos naturales y culturales, como lo refleja el inventario de atractivos turísticos, los mismos, que con un manejo adecuado de los recursos naturales y culturales ayudan a conservar el ecosistema natural, y potencian la difusión del conocimiento ancestral que poseen los indígenas sobre su entorno, siendo el bosque húmedo tropical amazónico el más sobresaliente con una jerarquía IV, el mismo que al estar ubicado en el parque nacional Yasuni, y declarado por la UNESCO patrimonio natural de la humanidad, contribuirá al desarrollo turístico de la región y de la comuna Kichwa Mandari Panga.

Las diversas actividades cotidianas de la comuna pueden ser explotadas, en torno al Patrimonio natural y cultural que posee, además el involucramiento del turista en este tipo de actividades que conduce a un interrelación entre la comuna y el turista, también cabe mencionar que el trazado de un sendero autoguiado, mejora la experiencia y percepción de los visitantes, como alternativa adicional facilitan el recorrido y a su vez aumentará la afluencia de turistas a la comuna Kichwa Mandari Panga.

El diseño de letreros informativos nos permite tener bien identificados los atractivos naturales por otro lado la necesidad de diversificación de la oferta turística por parte de los visitantes, resulta una 
exigencia hacia un mayor acercamiento turístico al territorio, es así como la búsqueda y puesta en valor de recursos potencialmente turísticos forman parte de la actividad de interpretación y valoración desde un enfoque de desarrollo de la comuma Kichwa Mandari Panga.

\section{References:}

1. Albrieu, F. \& Navarro. (2013). Desarrollo de nuevos productos turísticos a partir de recursos naturales en áreas urbanas. 15th ed. Patagonia Austral: Rio Gallegos, p.19.

2. Arizona, T. (2011). Soil Taxonomy. 38th ed. Madison: Soil Science society of America, p.11.

3. Josep, F. (2010). J. M, \& Querol Gómez Nivelación de Terrenos por Regresión Tridimensional. 1st ed. Tortosa: Centro Asociado de Tortosa (UNED), p.489.

4. Molina, G.E. (2011). Diseño y Construcción de un Sendero Interpretativo en la Asociación Pita - Pedregal, Cantón Mejía, Provincia de Pichincha. 1st ed. Latacunga: Latacunga/ UTC, p.149.

5. Chacón, R. M., \& Pellegrini- Blanco, N. C. (2017). El Paradigma de la Sostenibilidad, un Enfoque Educativo. 3rd ed. Simón Bolívar: Universidad Simón Bolívar, Venezuela, Ágora de heterodoxias p.83.

6. Nail, Wearing, J. (2017). Ecoturismo, Impacto, Tendencias y Posibilidades. 69th ed. Madrid: Síntesis. 269.p

7. Fundación Biosfera. (2015). Informaciones sobre Ecoturismo.

8. GADPO. (2014). Reglamento-incentivos-escolares.

9. MINTUR. (2007). Manual de señalética turística.

10. PUCE. (2011). Dinámica del Bosque Yasuní. Ecuador.

11. García Bautista, D. F., \& Mahecha Gutiérrez, S. A. (2017). Estudio de factibilidad técnica y ambiental de los procesos turísticos y su impacto en el paisaje para un sendero en zona rural de Bogotá. Cuadernos de Geografia-Revista Colombiana de Geografía, 26(2), 195-218. 